\title{
Deformation but not migration and rotation - a model study on vesicle biomechanics in a uniform DC electric field
}

\author{
Hui Ye*1, Austen Curcuru ${ }^{2}$ \\ ${ }^{1}$ Department of Biology, Loyola University Chicago, Chicago, IL, USA \\ ${ }^{2}$ Department of Physics, Loyola University Chicago, Chicago, IL, USA
}

Received: July 29, 2016

DOI: $10.5430 /$ jbei.v3n1p18
Accepted: September 27, $2016 \quad$ Online Published: October 14, 2016

URL: http://dx.doi.org/10.5430/jbei.v3n1p18

\begin{abstract}
Background: Biological cells migrate, deform and rotate in various types of electric fields, which have significant impact on the normal cellular physiology. To investigate electrically-induced deformation, researchers have used artificial giant vesicles that mimic the phospholipid bilayer cell membrane. Containing primarily the neutral molecule phosphatidylcholine, these vesicles deformed under evenly distributed, strong direct current (DC) electric fields. Interestingly, they did not migrate or rotate. A biophysical mechanism underlying the kinematic differences between the biological cells and the vesicles under electric stimulation has not been worked out.

Methods: We modeled the vesicle as a leaky, dielectric sphere and computed the surface pressure, rotation torques and translation forces applied on the vesicle by a DC electric field. We compared these measurements with those in a biological cell that contains non-zero, intrinsic charges (carried by the functional groups on the membrane).

Results: For both the vesicle and the cell, the electrically-induced charges interacted with the local electric field to generate radial pressure for deformation. However, due to the symmetrical distribution of both the charges and the electric field on the vesicle/cell surface, the electric field could not generate net translation force or rotational torques. For a biological cell, the intrinsic charges carried by the cell membrane could account for its migration and rotation in a DC electric field.

Conclusion: Results from this work suggests an interesting control diagram of cellular kinematics and movements by the electric field: cell deformation and migration can be manipulated by directly targeting different charged groups on the membrane. Fate of the cell in an electric field depends not only on the delicately controlled field parameters, but also on the biological properties of the cell.
\end{abstract}

Key Words: Electric field, Biomechanics, Cell, Deformation, Migration, Rotation

\section{INTRODUCTION}

Interaction between the electric field and biological cells leads to biomechanical alterations of the cells. ${ }^{[1]}$ When positioned inside a strong electric field, cell membranes can demonstrate deformation. ${ }^{[2,3]}$ For example, an externally applied electric field could generate undulation on a conductive cell membrane. ${ }^{[4]}$ A direct current (DC) electric field could cause elongation of human adipose tissue-derived stem cells, in the direction that was perpendicular to the field. ${ }^{[5]}$ Pulsed electromagnetic field (PEMF) introduced

\footnotetext{
${ }^{*}$ Correspondence: Hui Ye; Email: hye1 @luc.edu; Address: Department of Biology, Loyola University Chicago Quinlan Life Sciences Education and Research Center, 1032 W. Sheridan Rd., Chicago, IL 60660, USA.
} 
long-term morphological alterations in the cultured human chondrocytes. ${ }^{[6]}$ The biomechanical phenomena of cytoskeleton change could be further manifested when cells sense the mechanical signals and transduce them into a cascade of biochemical signals, including DNA and RNA synthesis, hypertrophy (increased cell size), proliferation, apoptosis, migration, and extracellular matrix remodeling. ${ }^{[7]}$ Under extremely intensive electric field, pores formed on the cell membrane and the membrane became permeable (electroporation). ${ }^{[8]}$ Electroporation has been widely used for cancer treatment by enhancing the delivery of antitumor drugs into tumor tissue and for gene transfection into single cells. ${ }^{[9]}$

Electric fields can also cause cell migration. Publications describing cell migration under an applied electric field (i.e., galvanotaxis or electrotaxis) can be retrieved from the 1920's. ${ }^{[10]}$ Current studies show that electric fields could play important roles in axonal guidance, cell electrophoresis, ${ }^{[11]}$ migration of stem cells, ${ }^{[12]}$ and movement of neurons within the neural networks. ${ }^{[13]}$ It is suggested that mechanical forces generated by the direct interaction between local electric field and the charges on the cell membrane could play significant roles in mediating cell migration. ${ }^{[14]}$ In addition, although rarely seen, cells can demonstrate rotation under the control of rotational torques that were generated by circularly polarized electric field. ${ }^{[15]}$

To investigate field-induced cellular biomechanics, closed lipid bilayer membranes (vesicles) have been studied. ${ }^{[16,17]}$ It was found that the vesicles primarily underwent membrane deformation under electric fields. For example, Sadik et al. ${ }^{[18]}$ reported that the vesicles exhibited elongation along the direction of the electric field. Riske and Dimova ${ }^{[16]}$ reported that vesicles subjects to DC electric pulses could be deformed into elliptical or cylindrical shapes. Interestingly, there is no evidence of vesicle migration and rotation in these experiments, even if the field intensity was as large as $2.0 \mathrm{kV} / \mathrm{cm}$, when electroporation could be observed. ${ }^{[18]}$

In order to theoretically understand vesicle deformation under the electric field, simplified vesicle models have been built to analyze vesicle biomechanics. ${ }^{[19-21]}$ Hyuga et al. suggested that interactions between the field and charges that accumulate on the vesicle surface could generate membrane deformation. ${ }^{[22]}$ We designate these charges as induced surface charges, with a density $\rho_{s}$. Dimova et al. ${ }^{[23]}$ performed extensive analysis on the vesicle shape in a time-varying electric field, and found it depended on the intra-to-extra-vesicle conductivity ratio. Vlahovska et al. ${ }^{[24]}$ studied the vesicle shape by considering the hydrodynamic, electric, bending, and tension stresses exerted on the vesicle. However, these modeling works were mainly used to explain the deformation

Published by Sciedu Press of the vesicles, and have not attempted to explicitly explain the lack of vesicle migration and rotation in a DC electric field.

In the aforementioned vesicle experiments, the spherical vesicles are formed with L-a-phosphatidylcholine molecule. ${ }^{[16,18]}$ The phosphatidylcholine headgroup is a neutral molecule as a whole, since it contains a positively charged choline group and negatively charged phosphate and carbonyl groups. ${ }^{[25]}$ In contrast, biological cells carry charged membrane proteins, which reside in the lipid headgroups within the membrane. ${ }^{[26]}$ The charged headgroups contain both cationic and anionic functional groups that contribute to the net electric field at membrane surfaces. The intensity of the field could reach a value of $10^{5} \mathrm{~V} / \mathrm{cm}$, which is capable of strongly attracting cationic proteins, peptides, and ions. ${ }^{[27,28]}$ We designate these charges as intrinsic surface charges, with a density $\rho_{p}$. These intrinsic charges are known to play a significant role in cell migration in the electric filed, or electrophoresis. ${ }^{[11]}$ We therefore hypothesize that a lack of migration and rotation in vesicles exposed in the DC electric field was due to the lack of intrinsic charges on the artificial vesicles, and that the induced surface charge alone, is insufficient in generating rotation and migration forces in the vesicle.

To test this hypothesis, we will compute induced surface charges, deformation pressure, translational force, and rotation torque in a simple spherical vesicle model, in a strong DC electric field. We adopted the common assumption among different theoretical models that the vesicle is a leaky dielectric particle of fixed shape, ${ }^{[18,22]}$ and treated the vesicle as a spherical structure with certain conductance and dielectricity. ${ }^{[29,30]}$ The membrane thickness is taken to be zero and the electrical resistance of the membrane is assumed to be negligible, ${ }^{[18,22]}$ to account for the poration and leakage under strong electric field intensity. Our model generated analytical expression of the radial pressure on the membrane, and confirmed the experimental observation that the shape of deformation depended on the intra-to-extra-vesicle conductivity ratio. Due to its symmetrical distribution on the vesicle surface, the electrically induced-pressure did not generate net translation force nor rotational torques in the modeled spherical vesicle.

\section{MeTHODS}

The spherical vesicle model is based on several previous works, ${ }^{[18,24]}$ which consider the vesicle in aqueous solution to have a permeable, conducting membrane with zero thickness. The model contains a homogeneous sphere (i) placed inside the conductive medium (o). The center of the vesicle is located at point $O$. Each region is considered homoge- 
nous and isotropic with electric conductivities $\sigma_{o}, \sigma_{i}$, respectively. The dielectric permittivities of the two media are $\varepsilon_{0}, \varepsilon_{i}$, respectively. The radius of the vesicle is $R$. The vesicle is exposed to an externally applied uniform electric field $\vec{E}=E \vec{Z}$, where $\vec{Z}$ is the unitary vector in the direction of the field (see Figure 1).
A

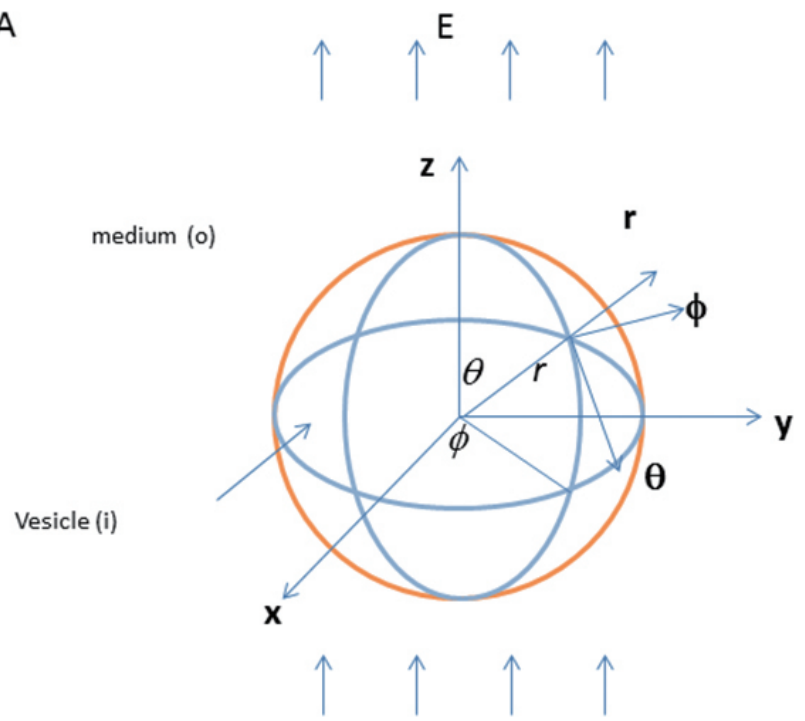

B

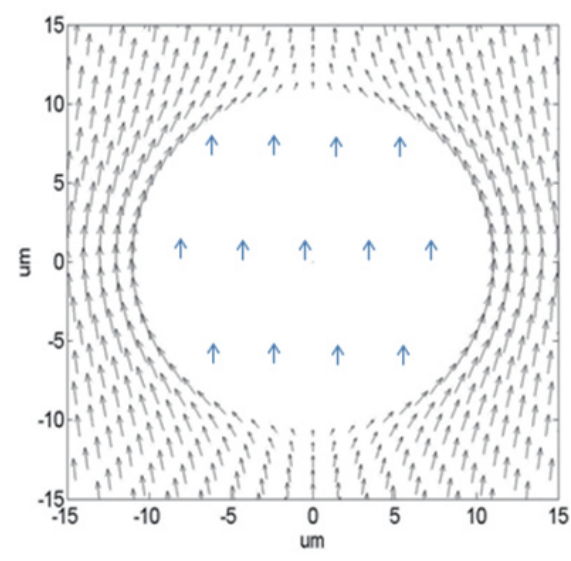

Figure 1. A. Spherical coordinates for a model vesicle inside a DC electric field. The field $\mathrm{E}$ is in the z-direction. B. Electric field distribution around and inside the vesicle

We derived the analytical expressions of the electric potentials in the medium and inside the vesicle, by solving Laplace's equation $\nabla V=0$. Four boundary conditions were considered: (1) The potential and (2) the normal components of the current density are continuous across the vesicle surface; (3) The electric field at an infinite distance is not perturbed by the presence of the vesicle; and (4) the potential inside the vesicle is finite. The electric field distributions in all regions were calculated as $\vec{E}=-\nabla V$, where $V$ is the potential.

All model parameters are listed in Table 1. Intensity of the electric field was chosen to be $200,000 \mathrm{~V} / \mathrm{m}$, an intensity that was sufficient for vesicle deformation. ${ }^{[16]}$ Similar intensity electric field has also been used to cause membrane poration. ${ }^{[18]}$ The rest of the parameters are chosen from the literature as indicated in the table. Derivations of the equations were performed with Mathematica 6.0 (Wolfram Research, Inc. Champaign, IL). Numerical simulations were performed with Matlab 7.4.0 (The MathWorks, Inc. Natick, MA).

\section{RESUlts}

The electrical forces applied on the vesicle surface have both radial and tangential components, which could cause membrane deformation and generation of rotational torque, respectively. We will first calculate the distribution of the electric field and the induced charges on the vesicle surface. We will then derive the radial pressure, rotation torques and migration forces on the vesicle.

Table 1. Model Parameters. Parameters were chosen based on the following literatures. (1) Blood serum at $35^{\circ} \mathrm{C} ;{ }^{[31]}$ (2) In Ref. ${ }^{[32]}$ (3) In Ref. ${ }^{[33]}$ (4) In Ref. ${ }^{[18]}$ for vesicle deformation in the electric field.

\begin{tabular}{llll}
\hline Parameters & $\begin{array}{l}\text { Standard } \\
\text { value }\end{array}$ & $\begin{array}{l}\text { Lower } \\
\text { limit }\end{array}$ & $\begin{array}{l}\text { Upper } \\
\text { limit }\end{array}$ \\
\hline $\begin{array}{l}\text { Extracellular conductivity } \\
\left(\sigma_{o}, \mathrm{~S} / \mathrm{m}\right)\end{array}$ & $0.3^{(2)}$ & $0.01^{(2)}$ & $1.2^{(1)}$ \\
$\begin{array}{l}\text { Cytoplasmic conductivity } \\
\left(\sigma_{i}, \mathrm{~S} / \mathrm{m}\right)\end{array}$ & $0.3^{(2)}$ & $0.2^{(2)}$ & $1.2^{(2)}$ \\
$\begin{array}{l}\text { Extracellular dielectric } \\
\text { permittivity }\left(\varepsilon_{o}, \text { As/Vm) }\right.\end{array}$ & $6.4 \times 10^{-10(3)}$ & - & - \\
$\begin{array}{l}\text { Cytoplasmic dielectric } \\
\text { permittivity }\left(\varepsilon_{i}, \text { As/Vm) }\right.\end{array}$ & $6.4 \times 10^{-10(3)}$ & - & - \\
$\begin{array}{l}\text { Vesicle radius }(\mathrm{R}, \mu \mathrm{m}) \\
\begin{array}{l}\text { Electric field intensity } \\
(\mathrm{E}, \mathrm{V} / \mathrm{m})\end{array}\end{array}$ & $10^{(3)}$ & $5^{(3)}$ & $100^{(3)}$ \\
\hline
\end{tabular}

\subsection{Electric field distribution around a vesicle}

The solution of Laplace's equation in spherical coordinates is 
$V=\sum_{m, n}\left[\left(a_{n m} r^{n}+\frac{b_{n m}}{r^{n+1}}\right) \cos m \phi P_{n}^{m}(\cos \theta)+\left(c_{n m} r^{n}+\frac{d_{n m}}{r^{n+1}}\right) \sin m \phi P_{n}^{m}(\cos \theta)\right]$

where $P_{n}^{m}(\cos \theta)$ is the associated Legendre function $(\mathrm{n}=$ $0 \ldots \infty, \mathrm{m}=0 \ldots \mathrm{n})$.

The unknown coefficients are solved and substituted into equation (1). The potentials in the medium and in the cytoplasm respectively are:

$$
\begin{aligned}
& V_{o}=\left(\frac{\sigma_{i}-\sigma_{o}}{2 \sigma_{o}+\sigma_{i}} \frac{R^{3}}{r^{2}}-r\right) E \cos \theta \\
& V_{i}=\frac{-3 \sigma_{o}}{2 \sigma_{o}+\sigma_{i}} E r \cos \theta
\end{aligned}
$$

Electric field distribution in the medium and inside the vesicle is calculated by

$$
\vec{E}=-\nabla V=-\left(\frac{\partial V}{\partial r}, \frac{1}{r} \frac{\partial V}{\partial \theta}, \frac{1}{r \sin \theta} \frac{\partial V}{\partial \phi}\right)
$$

The expression derived for the electric field, outside the vesicle (o) is:

$$
\begin{aligned}
& E_{o r}=\left(1+\frac{2 R^{3}}{r^{3}} \frac{\sigma_{i}-\sigma_{o}}{2 \sigma_{o}+\sigma_{i}}\right) E \cos \theta \\
& E_{o \theta}=\left(-1+\frac{R^{3}}{r^{3}} \frac{\sigma_{i}-\sigma_{o}}{2 \sigma_{o}+\sigma_{i}}\right) E \sin \theta \\
& E_{o \phi}=0
\end{aligned}
$$

Close to the vesicle surface $(r=R)$

$$
\begin{aligned}
& E_{o r}=\frac{3 \sigma_{i}}{2 \sigma_{o}+\sigma_{i}} E \cos \theta \\
& E_{o \theta}=-\frac{3 \sigma_{o}}{2 \sigma_{o}+\sigma_{i}} E \sin \theta \\
& E_{o \phi}=0
\end{aligned}
$$

The expressions derived inside the vesicle $(i)$ are:

$$
\begin{aligned}
& E_{i r}=\frac{3 \sigma_{o}}{2 \sigma_{0}+\sigma_{i}} E \cos \theta \\
& E_{i \theta}=-\frac{3 \sigma_{o}}{2 \sigma_{o}+\sigma_{i}} E \sin \theta \\
& E_{i \phi}=0
\end{aligned}
$$

Equations 5 and 6 can be validated by letting $\sigma_{o}=\sigma_{i}$, a situation when there is no vesicle positioned in the field. This

Published by Sciedu Press yields $E_{o r}=E_{i r}=E \cos \theta$ and $E_{o \theta}=E_{i \theta}=E \sin \theta$, respectively, which is essentially the externally applied electric field. Plotting the electric field distribution revealed that presence of the vesicle perturbs the fields (see Figure 1B). Tissue heterogeneity and anisotropic properties affect electric field distribution, as has been shown previously. ${ }^{[34]}$

\subsection{Induced electric charges on the vesicle surface}

The externally applied electric field can induce electric charges across the two non-homogeneous physical media. ${ }^{[35]}$ Surface charge distribution depends on the dielectric properties of the biological interface. Surface charges induced by the external field on vesicle surface are calculated by

$$
\rho_{s}=\left(\vec{D}_{o}-\vec{D}_{i}\right) \vec{r}
$$

where $\overrightarrow{D_{o}}$ and $\vec{D}_{i}$ denote displacements on both sides of the vesicle surface, respectively. $\vec{r}$ denotes a unitary vector that is perpendicular to the surface. Since $\vec{D}=\varepsilon \vec{E}$, surface charge density on the vesicle surface becomes

$$
\rho_{s}(R, \theta, \phi)=\varepsilon_{o} E_{o r}-\varepsilon_{i} E_{i r}=\frac{3\left(\sigma_{i} \varepsilon_{o}-\sigma_{o} \varepsilon_{i}\right)}{2 \sigma_{o}+\sigma_{i}} E \cos \theta
$$

It is interesting to note that the density of induced electric charges $\left(\rho_{s}\right)$ is independent of vesicle size. The $\cos \theta$ term in equation (8) indicates that the induced charges have different signs on the two vesicle poles (see Figure 2). For $\mathrm{E}=$ $250 \mathrm{~V} / \mathrm{m}, \rho_{s}=1.728 \times 10^{-7} \mathrm{C} / \mathrm{m}^{2}$ or charges $/ \mu \mathrm{m}^{2}$ on the poles $\left(\sigma_{o}=0.3 \mathrm{~S} / \mathrm{m}, \sigma_{i}=1.2 \mathrm{~S} / \mathrm{m}\right)$. This density is insignificant in comparison with the intrinsic charges carried by the proteins on the cell membrane. For $E=200,000$ $\mathrm{V} / \mathrm{m}$, the electric density is $\rho_{s}=1.38 \times 10^{-4} \mathrm{C} / \mathrm{m}^{2}$, or charges $/ \mu \mathrm{m}^{2}$, a value that is comparable to the density of the intrinsic charges. ${ }^{[14]}$ Since the induced charges could not leave the vesicle surface, the net induced charge on the vesicle should be zero, ${ }^{[36]}$ as shown by

$$
Q_{s}=\iint_{\theta, \phi} \rho_{s} d a=\iint_{\theta, \phi} \rho_{s} R^{2} \sin \theta d \theta d \phi=0
$$

Here, $d \vec{a}=R^{2} \sin \theta d \theta d \varnothing \vec{r}$ is a surface element in the $\vec{r}$ direction.

\subsection{Surface pressure and torques generated by the in- teraction between the electric field and the induced surface charges $\rho_{s}$}

Pressure on the membrane could introduce three morphological changes for the vesicle: (1) pulling/compression, (2) rotation around vesicle axes, and (3) translocation. 


\subsubsection{Radial forces for membrane deformation}

To investigate the pressure that might affect curvature of the vesicle membrane, we computed the pressure in the $\vec{r}$ direction. Pressure on a charged surface equals the product of the charge with the averaged field intensities on both sides of the surface. ${ }^{[37]}$ Evaluated on a patch of surface area, the pressure is

$$
P_{r}=\frac{1}{2}\left(E_{o r}+E_{i r}\right) \rho_{s}=\frac{9\left(\sigma_{i}+\sigma_{o}\right)\left(\sigma_{i} \varepsilon_{o}-\sigma_{o} \varepsilon_{i}\right)}{2\left(2 \sigma_{o}+\sigma_{i}\right)^{2}} E^{2} \cos ^{2} \theta
$$

The direction of the radial forces is dependent on the electric parameters of the medium and the cytoplasm $\sigma_{i} \varepsilon_{o}-\sigma_{o} \varepsilon_{i}$. Since $\varepsilon_{o}$ and $\varepsilon_{i}$ have comparable values (see Table 1), our model predicts that deformation of the vesicle axis depends

A
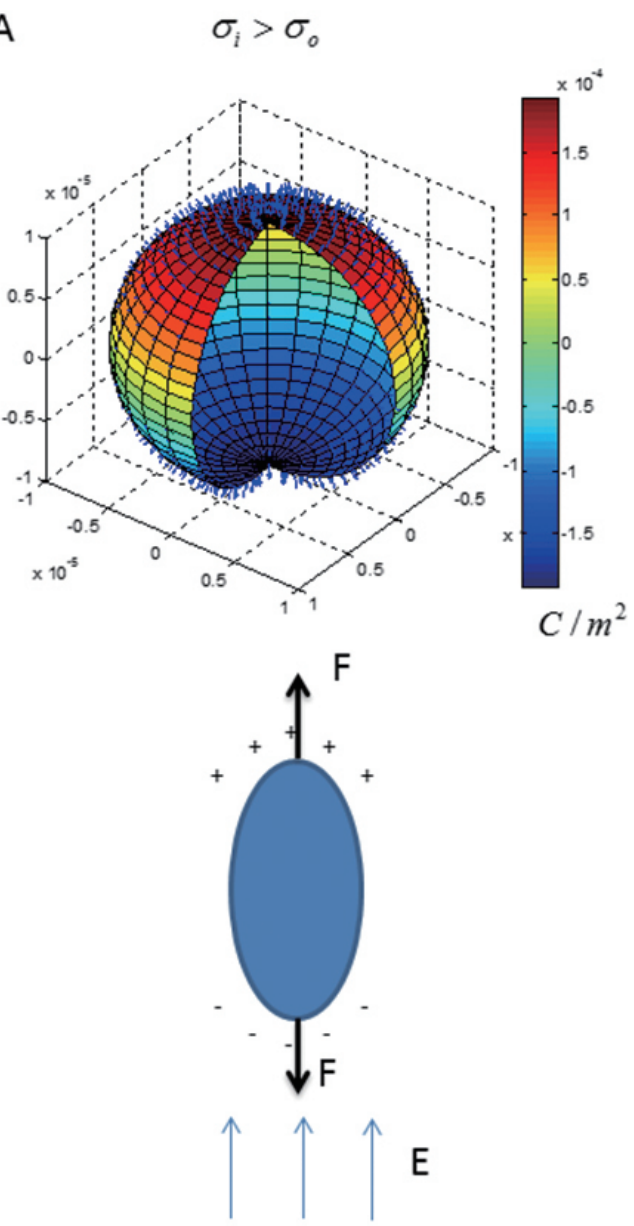

on the ratio $\sigma_{i} / \sigma_{o}$. Prolate deformation will occur along the symmetry axis that aligns parallel to the field for higher conductive cytoplasm (see Figure 2A), and an oblate deformation will occur for higher conductive medium outside (see Figure 2B). It is also worth noticing that larger vesicles may experience greater radial forces. Furthermore, this pressure is proportional to $E^{2}$, as has been observed experimentally. ${ }^{[18]}$ When $\sigma_{o}=1.2 \mathrm{~S} / \mathrm{m}$ and $\sigma_{i}=0.3 \mathrm{~S} / \mathrm{m}$ were considered, the calculated pressure is $21.3 \mathrm{~N} / \mathrm{m}^{2}$. This is comparable to the traction force measured by Curtze et al. ${ }^{[38]}$ in the osteoblast-like cells within a DC electric field. These calculated pressures are also comparable with the ones that are sufficient in causing membrane deformation, such as atomic force microscopy measurement, micropipette aspiration, magnetic bead microrheology (twisting and pulling) or optical trapping. ${ }^{[7]}$

B
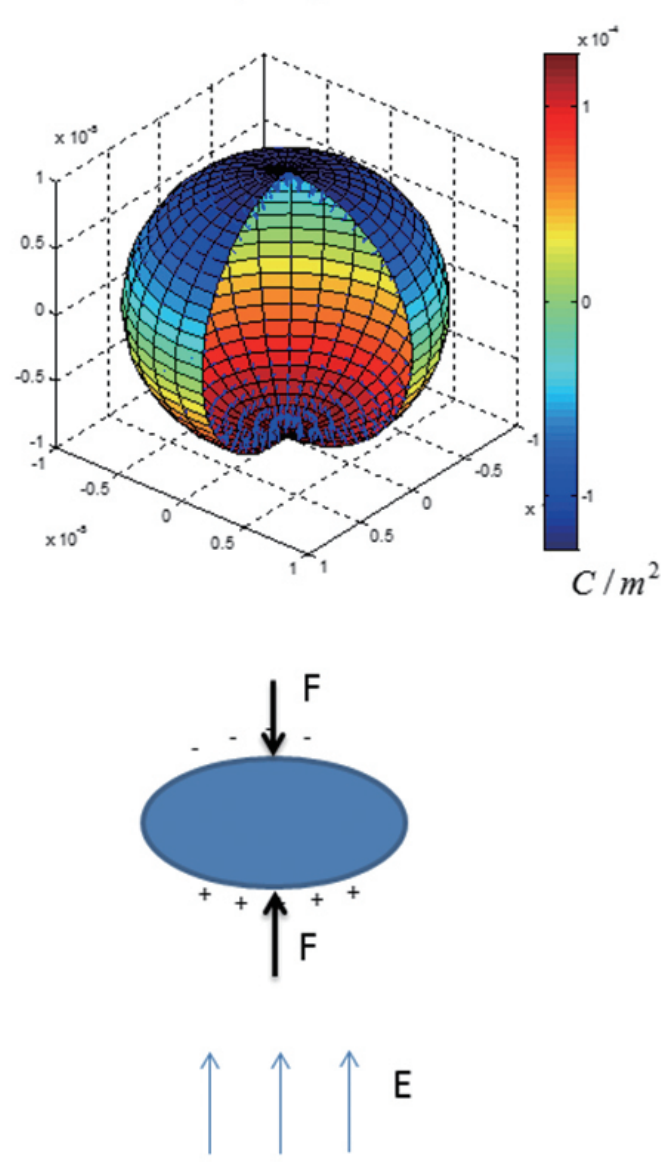

Figure 2. Induced charges on the vesicle surface and its contribution to membrane deformation. A. $\sigma_{i}>\sigma_{o}\left(\sigma_{o}=0.3 S / m\right)$ and $\sigma_{i}=1.2 S / m$, coulomb forces (arrows, computed with equation 10) generated by the interaction between the induced charges (color map, computed with equation 8 ) and the electric field elongates the vesicle in the field direction; B. $\sigma_{i}<\sigma_{o}\left(\sigma_{o}=1.2 S / m\right)$ and $\sigma_{i}=0.3 S / m$, coulomb forces compress the vesicle in the field direction. The intensity of the field is $200,000 \mathrm{~V} / \mathrm{m}$ 


\subsubsection{Torques for rotation}

Vesicle rotation can be predicted by computing shear torque on its surface. ${ }^{[15,29]}$ The tangential $(\vec{\theta}$ and $\vec{\phi})$ components of the coulomb forces generate torques that rotate the vesicle. The overall torque in the direction $\vec{\theta}$ was

$$
\begin{aligned}
& \vec{T}_{\theta}=\iint_{\theta, \phi}(R \vec{R}) \times\left(E_{o \theta} q \rho_{s} d a \vec{\theta}\right) \\
& =\iint_{\theta, \phi} R\left(-\frac{3 \sigma_{o}}{2 \sigma_{o}+\sigma_{i}}\right) E \sin \theta q \frac{3\left(\sigma_{i} \varepsilon_{o}-\sigma_{o} \varepsilon_{i}\right)}{2 \sigma_{o}+\sigma_{i}} E \cos \theta R^{2} \sin \theta \vec{\phi} d \theta d \phi
\end{aligned}
$$

To be able to integrate the unit vector $\vec{\phi}$, we wrote $\vec{\phi}$ as a linear combination of $\vec{x}, \vec{y}, \vec{z}, \vec{\phi}=-\sin \phi \vec{x}+\cos \phi \vec{y}$. After rewriting this equation, we have

$$
\begin{aligned}
& \vec{T}_{\theta}=\frac{9 \sigma_{o}\left(\sigma_{i} \varepsilon_{o}-\sigma_{o} \varepsilon_{i}\right)}{\left(2 \sigma_{o}+\sigma_{i}\right)^{2}} E^{2} R^{3}\left[\bar{x} \iint_{\theta, \phi} \sin ^{2} \theta \cos \theta(-\sin \phi) d \theta d \phi+\bar{y} \iint_{\theta, \phi} \sin ^{2} \theta \cos \theta \cos \phi d \theta d \phi\right] \\
& =0
\end{aligned}
$$

This is because of the azimuthal symmetry of both the surface charges and the electric field on the vesicle's surface. In addition, since the $\vec{\phi}$ component of the electrical field was zero, we obtained

$$
\vec{T}_{\phi}=\iint_{\theta, \phi}(R \vec{r}) \times\left(E_{o \phi} \rho_{s} d a \vec{\phi}\right)=0
$$

Thus, the electric force could not generate rotation torque on the vesicle surface.

\subsubsection{Translation forces for migration}

Expressions of the electric field in $(x, y, z)$ directions could be obtained through transformation from spherical to rectangular coordinates,

$$
\left[\begin{array}{c}
E_{o x} \\
E_{o y} \\
E_{o z}
\end{array}\right]=\left[\begin{array}{ccc}
\sin \theta \cos \phi & \cos \theta \cos \phi & -\sin \phi \\
\sin \theta \sin \phi & \cos \theta \sin \phi & \cos \phi \\
\cos \theta & -\sin \theta & 0
\end{array}\right]\left[\begin{array}{c}
E_{o r} \\
E_{o \theta} \\
E_{o \phi}
\end{array}\right]
$$

Immediately outside the vesicle, we have

$$
\begin{aligned}
& E_{o x}=\frac{3\left(\sigma_{i}-\sigma_{o}\right)}{2 \sigma_{o}+\sigma_{i}} E \sin \theta \cos \theta \cos \phi \\
& E_{o y}=\frac{3\left(\sigma_{i}-\sigma_{o}\right)}{2 \sigma_{o}+\sigma_{i}} E \sin \theta \cos \theta \sin \phi \\
& E_{o z}=\frac{3 \sigma_{i}}{2 \sigma_{o}+\sigma_{i}} E \cos ^{2} \theta+\frac{3 \sigma_{o}}{2 \sigma_{o}+\sigma_{i}} E \sin ^{2} \theta
\end{aligned}
$$

Similarly, immediately under the vesicle surface, using the transformation matrix

$$
\left[\begin{array}{l}
E_{i x} \\
E_{i y} \\
E_{i z}
\end{array}\right]=\left[\begin{array}{ccc}
\sin \theta \cos \phi & \cos \theta \cos \phi & -\sin \phi \\
\sin \theta \sin \phi & \cos \theta \sin \phi & \cos \phi \\
\cos \theta & -\sin \theta & 0
\end{array}\right]\left[\begin{array}{c}
E_{i r} \\
E_{i \theta} \\
E_{i \phi}
\end{array}\right]
$$

We have

$$
\begin{aligned}
& E_{i x}=0 \\
& E_{i y}=0 \\
& E_{i z}=\frac{3 \sigma_{o}}{2 \sigma_{o}+\sigma_{i}} E
\end{aligned}
$$

The overall translation force in the $x, y$ and $z$ directions are:

$$
\begin{aligned}
& F_{x}=\iint_{\theta, \phi} E_{o x} \rho_{s} d a=0 \\
& F_{y}=\iint_{\theta, \phi} E_{o y} \rho_{s} d a=0 \\
& F_{z}=\iint_{\theta, \phi} E_{o z} \rho_{s} d a=0
\end{aligned}
$$

Therefore, interactions between the induced surface charges and the electric field could not provide translational force for the vesicle.

\section{Discussion}

Here we propose a theoretical model to study the biomechanics of a vesicle inside a uniform DC electric field to address vesicle deformation, and its lack of migration and rotation in this field. Our model confirmed the experimental observation that changes in the vesicle shape depends on the intra-to-extra-vesicle conductivity ratio, and field intensity. The induced electric charges are the primary reason that radial force for vesicle compression is generated. Due to the symmetrical distributions of both the local electric field around the vesicle, and the induced charges on the vesicle surface, the vesicle does not experience translational forces and/or rotation torques. For a biological cell, its migration and rotation inside an electric field could be due to the intrinsic charges on the cell membrane, for which an artificial vesicle does not possess. This work supports our hypothesis that biological effects of electric stimulation is a function of both the field parameters and the cellular properties. ${ }^{[39]}$

\subsection{Induced charges and vesicle deformation}

Our model predicts that the direction of vesicle deformation depends on the dielectric properties of the vesicle (see Figure 2). Prolate deformation will occur along the symmetry axis that aligns parallel to the field if the cytoplasm is more conductive than the medium (see Figure 2A), and an oblate 
deformation will occur if the medium is more conductive than the cytoplasm (see Figure 2B). This phenomenon has been observed previously in the lipid vesicles that were subjected to a DC electric pulse. The vesicles deformed into prolate or oblate ellipsoids depending on the conductivities of the interior and suspending fluids. ${ }^{[23,40]}$ When the ratio is between 1.92 and 53.0, the vesicle exhibited prolate elongation in the direction of the electric field. Larger ratio $\left(\sigma_{i} / \sigma_{o}\right)$ is associated with stronger deformation. Our model also indicated that the radial pressure is proportional to $E^{2}$ (equation 10), which is supported by the observation that impact of membrane deformation by the aspect ratio is scaled quadratically with the field strength. ${ }^{[18]}$

A
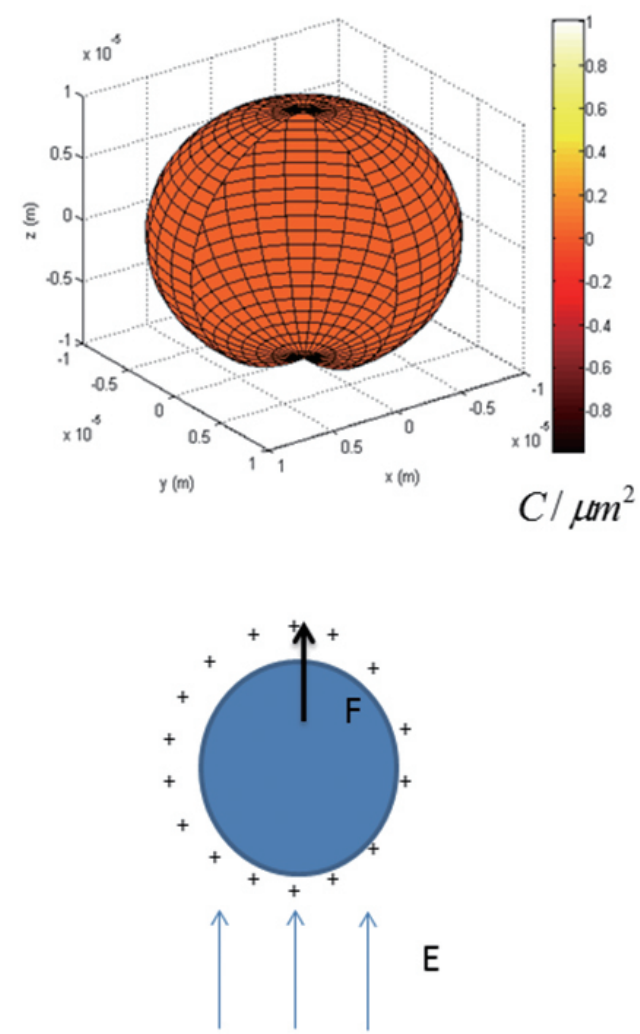

Under physiological conditions, the dielectric constant difference between the cytosol and the cell environment is trivial. This might explain the lack of significant cell deformation in comparison with vesicles, whose $\left(\sigma_{i} / \sigma_{o}\right)$ can be significant by adjusting the concentration of external solution. Nevertheless, it should be recognized that even a tiny deformation of the cell membrane could impose significant impact in directing intracellular signaling. ${ }^{[26]}$ Tiny, nanoscale forces are sufficient to activate cellular (mechanotransduction) signaling pathways. ${ }^{[41]}$ Compressive stress that shrinks the lateral intercellular space surrounding epithelial cells could trigger autocrine signaling. ${ }^{[42]}$ Kinetics of a variety of voltage-gated ion channels could be modulated by membrane tension. ${ }^{[43]}$

\section{B}
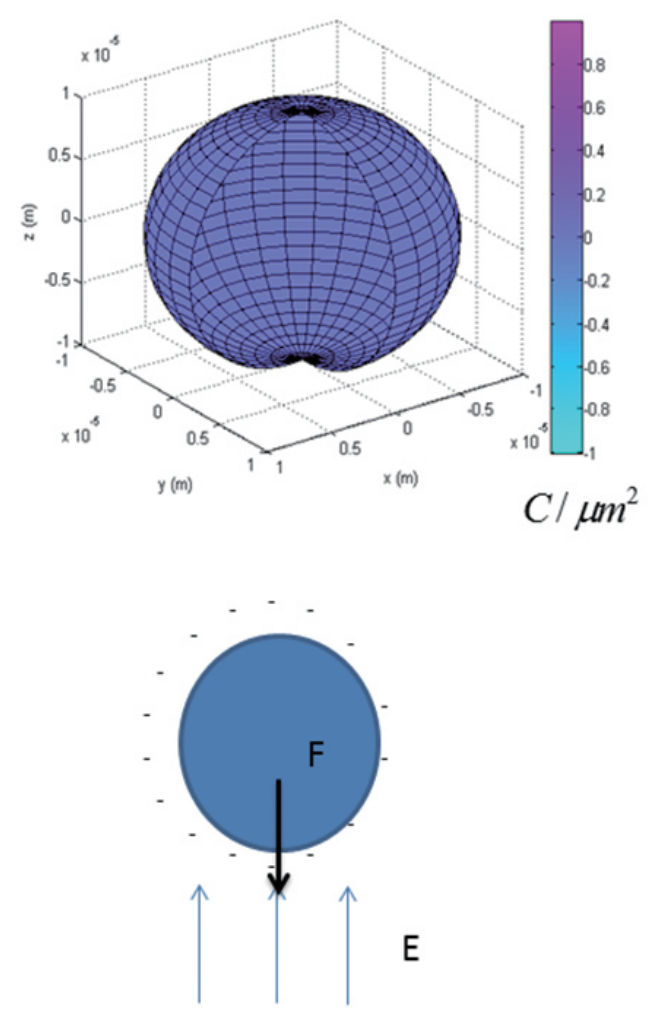

Figure 3. Intrinsic electric charges on the vesicle and its potential role in migration. A. Translation force is in the field direction for the cell that processes positive charges. B. Translation force is in the negative field direction if the cell possesses negative charges. In this plot, the charges density is $3.6 \times 10^{4}$ charges $/ \mu \mathrm{m}^{2}$ in (A), and $-3.6 \times 10^{4}$ charges $/ \mu \mathrm{m}^{2}$ in $(B)^{[14]}$

\subsection{Intrinsic charges and cell migration}

Our model provides a possible explanation for the lack of vesicle migration and rotation under large DC electric field, which is likely due to the symmetrical distribution of the induced charges on the membrane. This model assumes the surface charge in the lipid vesicles is neutral, therefore no translational force could be generated on the vesicle for its migration. In contrast, a biological cell possesses intrinsic charges $\left(\rho_{p}\right)$, which reside on the cell membrane lipids, or on the channel protein itself. Based on literature, we can assume the intrinsic charges being evenly distributed on the membrane with a net density of $\rho_{p}=3.6 \times 10^{4}$ charges $/ \mu \mathrm{m}^{2}{ }^{[14]}$ Then the cell will experience a force of $F=Q E,{ }^{[11]}$ where $Q$ is the net charge carried by the proteins or phospholipid head groups, and the $E$ is the local electric intensity (see Figure 3). For a vesicle with radius of $10 \mu \mathrm{m}, F=1.8 \times 10^{-9} \mathrm{~N}$, 
a force comparable to that can be used for cell migration or contraction $\left(10^{-9} N-10^{-5} N\right.$ in Ref. $\left.{ }^{[7]}\right)$.

The model thus produces a testable hypothesis of cellular biomechanics under electric field. We predict that alteration of intrinsic charges, by changing $\mathrm{pH}^{[11]}$ or by binding of calcium or magnesium to the surface charges, ${ }^{[14]}$ should be sufficient in changing cell mobility in electric fields. In contrast, it should generate little difference in the amount of membrane deformation, something that could be measured with an atomic force microscopy (AFM) tip. ${ }^{[44]}$ This prediction can be further tested using partially charged vesicles, such as those composed of lipid mixtures of phosphatidylcholine and phosphatidylglycerol or phosphatidylcholine and phosphatidylserine. ${ }^{[16]}$ The partially charged vesicle should demonstrate different cellular kinematics than neutral vesicles, such as some degree of migration.

\subsection{Significance of cellular properties in electric stimu- lation}

Since different cell types can carry different membrane charges, results from this study further support the idea that cellular properties affect the outcome of electric stimulation. Previously, geometric features of the cell, such as cell size ${ }^{[45]}$ shape, ${ }^{[46]}$ and its orientation to the field ${ }^{[47,48]}$ were found to be essential in understanding the consequence of electric stimulation. Furthermore, electrical properties of the biological cells, such as membrane conductivity ${ }^{[49]}$ and dielectricity, ${ }^{[50]}$ also play significant roles in the cellular response to the electric field. A detailed review on this topic could be found elsewhere. ${ }^{[39]}$

\subsection{Future directions}

Several assumptions have to be made in the model to simplify the calculation. It did not include other mechanical considerations such as shear elasticity of the membrane ${ }^{[3]}$ and ion movement through field-induced pores, which will affect electric fields ${ }^{[51]}$ and vesicle shapes. Second, the cell membrane, which represents a complex boundary compared to fluid-fluid interfaces, was not explicitly studied. Further work will include the capacitive property of the membrane. Third, the morphological structure of the cell influences the overall potential and charge distribution on the cell during electric stimulation. ${ }^{[52]}$ It is not known if such morphological complexity will apply to biomechanics analysis, which could be more appropriate with numerical methods such as finite element analysis. ${ }^{[8]}$ Fourth, for a biologically realistic cell model, the charged proteins contribute to the electric force and torques, and should be included in the analysis. It is worth noting that the distribution of the surface proteins could be geometrically inhomogeneous, which could play a significant role in membrane deformation. As an example, a transcellular oscillating electric field can cause vibration in the isolated outer hair cells of the cochlea. ${ }^{[53]}$ Furthermore, surface charges may dynamically change under pathological situations. These dynamic changes may affect membrane potential, ion channel distribution, and activities. $^{[27]}$ As an example, it is known that malignant cancer cells are associated with an increased negative surface charge. ${ }^{[54]}$ Finally, since cells could be polarized in the electric field, ${ }^{[45]}$ further endeavors should also consider membrane polarization ${ }^{[55]}$ and calcium influx that causes actin polymerization/depolymerization and actomyosin contractility. ${ }^{[56]}$

\section{ACKNOWLedgements}

The authors thank the Research Support Grant from Loyola University Chicago. Zohaib Sherwani and Kyle Wagner proofread the paper.

\section{CONFlicts OF INTEREST Disclosure}

The authors have no financial/conflicting interests to disclose.

\section{REFERENCES}

[1] Joshi RP, Hu Q. Analysis of cell membrane permeabilization mechanics and pore shape due to ultrashort electrical pulsing. Medical \& Biological Engineering \& Computing. 2010; 48(9): 83744. PMid:20635223. http://dx.doi.org/10.1007/s11517-0 10-0659-1

[2] Bryant G, Wolfe J. Electromechanical stresses produced in the plasma membranes of suspended cells by applied electric fields. The Journal of Membrane Biology. 1987; 96(2): 129-39. PMid:3599064. http://dx.doi.org/10.1007/BF01869239

[3] Engelhardt H, Sackmann E. On the measurement of shear elastic moduli and viscosities of erythrocyte plasma membranes by transient deformation in high frequency electric fields. Biophysical Journal.
1988; 54(3): 495-508. PMid:3207837. http://dx.doi.org/10. 1016/S0006-3495 (88) 82982-5

[4] Sens P, Isambert H. Undulation instability of lipid membranes under an electric field. Phys Rev Lett. 2002; 88(12). PMid:11909504. http://dx.doi.org/10.1103/PhysRevLett.88.128102

[5] Tandon N, Goh B, Marsano A, et al. Alignment and elongation of human adipose-derived stem cells in response to direct-current electrical stimulation. Conference proceedings: Annual International Conference of the IEEE Engineering in Medicine and Biology Society IEEE Engineering in Medicine and Biology Society Conference. 2009; 2009: 6517-21. PMid:19964171. http://dx.doi .org/10 . 1109/IEMBS. 2009. 5333142

[6] Jahns ME, Lou E, Durdle NG, et al. The effect of pulsed electro- 
magnetic fields on chondrocyte morphology. Medical \& Biological Engineering \& Computing. 2007; 45(10): 917-25. PMid:17701237. http://dx.doi.org/10.1007/s11517-007-0216-8

[7] Roger Kamm JLaMM. Cellular Nanomechanics. Springer Handbook of Nanotechnology (ed) B Bhushan. 2010.

[8] Bae C, Butler PJ. Finite element analysis of microelectrotension of cell membranes. Biomechanics and Modeling in Mechanobiology. 2008; 7(5): 379-86. PMid:17657517. http://dx.doi .org/10.10 07/s10237-007-0093-y

[9] Gehl J. Electroporation: theory and methods, perspectives for drug delivery, gene therapy and research. Acta Physiologica Scandinavica. 2003; 177(4): 437-47. PMid:12648161. http://dx.doi.org/10. 1046/j.1365-201X.2003.01093.x

[10] Coulter CB. The Isoelectric Point of Red Blood Cells and Its Relation to Agglutination. The Journal of General Physiology. 1921; 3(3): 309-23. PMid:19871866. http://dx.doi.org/10.1085/jgp.3 .3 .309

[11] Mehrishi JN, Bauer J. Electrophoresis of cells and the biological relevance of surface charge. Electrophoresis. 2002; 23(13): 1984 94. http://dx.doi.org/10.1002/1522-2683(200207) 23:13 <1984: : AID-ELPS1984>3.0.CD;2-U

[12] Meng X, Arocena M, Penninger J, et al. PI3K mediated electrotaxis of embryonic and adult neural progenitor cells in the presence of growth factors. Experimental Neurology. 2011; 227(1): 210-7. PMid:21092738. http://dx.doi.org/10.1016/j.expne urol.2010.11.002

[13] Jeong SH, Jun SB, Song JK, et al. Activity-dependent neuronal cell migration induced by electrical stimulation. Medical \& Biological Engineering \& Computing. 2009; 47(1): 93-9. PMid:19034544. http://dx.doi.org/10.1007/s11517-008-0426-8

[14] Lipman KM, Dodelson R, Hays RM. The surface charge of isolated toad bladder epithelial cells. Mobility, effect of $\mathrm{pH}$ and divalent ions. The Journal of General Physiology. 1966; 49(3): 501-16. PMid:5938824. http://dx.doi.org/10.1085/jgp. 49.3.501

[15] Foster KR, Sauer FA, Schwan HP. Electrorotation and levitation of cells and colloidal particles. Biophysical Journal. 1992; 63(1): 180 90. PMid:19431839. http://dx.doi.org/10.1016/S0006-349 5(92) 81588-6

[16] Riske KA, Dimova R. Electric pulses induce cylindrical deformations on giant vesicles in salt solutions. Biophysical Journal. 2006; 91(5): 1778-86. PMid:16766621. http://dx.doi.org/10.1529/bioph ysj.106.081620

[17] Kummrow M, Helfrich W. Deformation of giant lipid vesicles by electric fields. Physical Review A. 1991; 44(12): 8356-60. PMid:9905991.http://dx.doi.org/10.1103/PhysRevA.44.8 356

[18] Sadik MM, Li J, Shan JW, et al. Vesicle deformation and poration under strong dc electric fields. Physical review E, Statistical, nonlinear, and soft matter physics. 2011; 83(6 Pt 2): 066316. PMid:21797486. http://dx.doi.org/10.1103/PhysRevE.83.066316

[19] Mitov MD, Meleard P, Winterhalter M, et al. Electric-field-dependent thermal fluctuations of giant vesicles. Physical review E, Statistical physics, plasmas, fluids, and related interdisciplinary topics. 1993; 48(1): 628-31. PMid:9960632. http://dx.doi.org/10.1103/p hysreve.48.628

[20] Peterlin P. Frequency-dependent electrodeformation of giant phospholipid vesicles in AC electric field. Journal of Biological Physics. 2010; 36(4): 339-54. PMid:21886342. http://dx.doi .org/10. 1007/s10867-010-9187-3

[21] Hyuga H, Kinosita K, Wakabayashi N. Deformation of Vesicles under the Influence of Strong Electric-Fields. Jpn J Appl Phys. 1991; 30(5): 1141-8. http://dx.doi.org/10.1143/JJAP.30.1141
[22] Hyuga H, Kinosita K, Wakabayashi N. Deformation of Vesicles under the Influence of Strong Electric-Fields. Jpn J Appl Phys. 1991; 30(6): 1333-5. http://dx.doi.org/10.1143/Jjap.30.1333

[23] Dimova R, Riske KA, Aranda S, et al. Giant vesicles in electric fields. Soft Matter. 2007; 3(7): 817-27. http://dx.doi.org/10.1039 /b703580b

[24] Vlahovska PM, Gracia RS, Aranda-Espinoza S, et al. Electrohydrodynamic model of vesicle deformation in alternating electric fields. Biophysical Journal. 2009; 96(12): 4789-803. PMid:19527639. http://dx.doi.org/10.1016/j.bpj . 2009.03.054

[25] Pasenkiewicz-Gierula M, Takaoka Y, Miyagawa H, et al. Charge pairing of headgroups in phosphatidylcholine membranes: A molecular dynamics simulation study. Biophysical Journal. 1999; 76(3): 1228-40. PMid:10049307. http://dx.doi.org/10.1016/S0006 -3495 (99) $77286-3$

[26] Goldenberg NM, Steinberg BE. Surface charge: a key determinant of protein localization and function. Cancer Research. 2010; 70(4): 1277-80. PMid:20124473. http://dx.doi.org/10.1158 10008-5472. CAN-09-2905

[27] McLaughlin S, Poo MM. The role of electro-osmosis in the electricfield-induced movement of charged macromolecules on the surfaces of cells. Biophysical Journal. 1981; 34(1): 85-93. PMid:6894257. http://dx.doi.org/10.1016/S0006-3495 (81) 84838-2

[28] Olivotto M, Arcangeli A, Carla M, et al. Electric fields at the plasma membrane level: A neglected element in the mechanisms of cell signalling. Bioessays. 1996; 18(6): 495-504. PMid:8787537. http://dx.doi.org/10.1002/bies. 950180612

[29] Jones TB. Basic theory of dielectrophoresis and electrorotation. IEEE engineering in medicine and biology magazine: the quarterly magazine of the Engineering in Medicine \& Biology Society. 2003; 22(6): 33-42. PMid:15007989. http://dx.doi .org/10.1109/MEMB. 20 03.1304999

[30] Jones TB. Electromechanics of Particles. Cambridge University Press, New York; 1995.

[31] Sunderman FW. Rapid measurement of serum total base and estimation of serum sodium; an improved conductivity assembly. American Journal of Clinical Pathology. 1949; 19(7): 659-64. PMid:18145455.

[32] Kotnik T, Bobanovic F, Miklavcic D. Sensitivity of transmembrane voltage induced by applied electric fields - a theoretical analysis. Bioelectroch Bioener. 1997; 43(2): 285-91. http://dx.doi.org /10.1016/S0302-4598(97)00023-8

[33] Kotnik T, Miklavcic D. Theoretical evaluation of voltage inducement on internal membranes of biological cells exposed to electric fields. Biophysical Journal. 2006; 90(2): 480-91. http://dx.doi.org/1 0.1529 /biophys j.105.070771

[34] Astrom M, Lemaire JJ, Wardell K. Influence of heterogeneous and anisotropic tissue conductivity on electric field distribution in deep brain stimulation. Medical \& Biological Engineering \& Computing. 2012; 50(1): 23-32. PMid:22101515. http://dx.doi .org/10.10 07/s11517-011-0842-z

[35] Polk C, Song JH. Electric fields induced by low frequency magnetic fields in inhomogeneous biological structures that are surrounded by an electric insulator. Bioelectromagnetics. 1990; 11(3): 235-49. PMid:2268379. http://dx.doi.org/10.1002/bem. 225011030 5

[36] Voldman J. Electrical forces for microscale cell manipulation. Annual Review of Biomedical Engineering. 2006; 8: 425-54. PMid:16834563. http://dx.doi.org/10.1146/annurev.bio eng.8.061505.095739

[37] Griffiths DJ. Introduction to Electrodynamics, 3rd ed. 1999.

[38] Curtze S, Dembo M, Miron M, et al. Dynamic changes in traction forces with DC electric field in osteoblast-like cells. Jour- 
nal of Cell Science. 2004; 117(Pt 13): 2721-9. PMid:15150319. http://dx.doi.org/10.1242/jcs.01119

[39] Ye H, Steiger A. Neuron matters: electric activation of neuronal tissue is dependent on the interaction between the neuron and the electric field. Journal of Neuroengineering and Rehabilitation. 2015; 12: 65. PMid:26265444. http://dx.doi.org/10.1186/s1298 4-015-0061-1

[40] Aranda S, Riske KA, Lipowsky R, et al. Morphological transitions of vesicles induced by alternating electric fields. Biophysical Journal. 2008; 95(2): L19-21. PMid:18487308. http://dx.doi.org/10. 1529/biophysj. 108.132548

[41] Sniadecki NJ. A tiny touch: activation of cell signaling pathways with magnetic nanoparticles. Endocrinology. 2010; 151(2): 451-7. PMid:20016028. http://dx.doi.org/10.1210/en. 2009-0932

[42] Tschumperlin DJ, Dai GH, Maly IV, et al. Mechanotransduction through growth-factor shedding into the extracellular space. Nature. 2004; 429(6987): 83-6. PMid:15103386. http://dx.doi .org/10. 1038/nature02543

[43] Gu CX, Juranka PF, Morris CE. Stretch-activation and stretchinactivation of Shaker-IR, a voltage-gated $\mathrm{K}+$ channel. Biophysical Journal. 2001; 80(6): 2678-93. PMid:11371444. http://dx.doi.o $\mathrm{rg} / 10.1016 / \mathrm{S} 0006-3495(01) 76237-6$

[44] Zhang PC, Keleshian AM, Sachs F. Voltage-induced membrane movement. Nature. 2001; 413(6854): 428-32. PMid:11574890. http://dx.doi.org/10.1038/35096578

[45] Ye H, Cotic M, Carlen PL. Transmembrane potential induced in a spherical cell model under low-frequency magnetic stimulation. Journal of Neural Engineering. 2007; 4(3): 283-93. PMid:17873431. http://dx.doi.org/10.1088/1741-2560/4/3/014

[46] Gimsa J, Wachner D. Analytical description of the transmembrane voltage induced on arbitrarily oriented ellipsoidal and cylindrical cells. Biophysical Journal. 2001; 81(4): 1888-96. Epub 2001/09/22. PMid:11566763. http://dx.doi.org/10.1016/S 0006-3495 (01) 75840-7

[47] Kotnik T, Bobanovic F, Miklavcic D. Sensitivity of Transmembrane Voltage Induced by Applied Electric Fields-A Theoretical Analysis. Bioelectrochem Bioenerg. 1997; 43(2): 285-91. http: //dx.doi.org/10.1016/S0302-4598(97)00023-8
[48] Kotnik T, Miklavcic D. Analytical description of transmembrane voltage induced by electric fields on spheroidal cells. Biophysical Journal. 2000;79(2):670-9. Epub 2000/08/02. PMid:10920001. http://dx.doi.org/10.1016/S0006-3495(00)76325-9

[49] Ye H, Cotic M, Fehlings MG, et al. Influence of Cellular Properties on the Electric Field Distribution Around a Single Cell. Progress in Electromagnetic Research B. 2012; 39: 141-61. http: //dx.doi.org/10.2528/PIERB11122705

[50] Krasteva VT, Papazov SP, Daskalov IK. Peripheral nerve magnetic stimulation: influence of tissue non-homogeneity. Biomed Eng Online. 2003; 2: 19. Epub 2003/12/25. PMid:14693034. http: //dx.doi.org/10.1186/1475-925X-2-19

[51] Mossop BJ, Barr RC, Henshaw JW, et al. Electric fields around and within single cells during electroporation - A model study. Ann Biomed Eng. 2007; 35(7): 1264-75. PMid:17340194. http: //dx.doi.org/10.1007/s10439-007-9282-1

[52] Rattay F, Leao RN, Felix H. A model of the electrically excited human cochlear neuron. II. Influence of the three-dimensional cochlear structure on neural excitability. Hearing Research. 2001; 153(12): 64-79. PMid:11223297. http://dx.doi.org/10.1016/S03 78-5955(00) 00257-4

[53] Jen DH, Steele CR. Electrokinetic model of cochlear hair cell motility. The Journal of the Acoustical Society of America. 1987; 82(5): 166778. PMid:3693708. http://dx.doi.org/10.1121/1.395158

[54] Carter HB, Partin AW, Coffey DS. Prediction of metastatic potential in an animal model of prostate cancer: flow cytometric quantification of cell surface charge. The Journal of Urology. 1989; 142(5): 1338-41. PMid:2810530.

[55] Gao RC, Zhang XD, Sun YH, et al. Different roles of membrane potentials in electrotaxis and chemotaxis of dictyostelium cells. Eukaryotic Cell. 2011; 10(9): 1251-6. PMid:21743003. http://dx.d oi.org/10.1128/EC.05066-11

[56] Mycielska ME, Djamgoz MBA. Cellular mechanisms of directcurrent electric field effects: galvanotaxis and metastatic disease. J Cell Sci. 2004; 117(9): 1631-9. PMid:15075225. http://dx. doi . org $/ 10.1242 /$ jcs. 01125 